\section{Beabrs international program trains professionals in sustainable development}

\author{
A \\ workshop on global warming and carbon \\ sequestration offered recently by the Beahrs \\ Environmental Leadership Program in Berkeley \\ could fundamentally change the way Charles \\ Yamoah of Ghana approaches the problem of soil \\ degradation in Africa.
}

"Organic carbon is more productive than fertilizer alone," says Yamoah, most recently a soil scientist with the International Fertilizer Development Center. "Those are the techniques we need to use in Africa to keep the land productive."

Based at UC Berkeley's Center for Sustainable Resource Development in the College of Natural Resources, the Beahrs program was founded in 2000 with seed money from Carolyn and Richard Beahrs, UC Berkeley alumni now based in New York City. "They were interested in putting science to work in solving global environmental problems and promoting interdisciplinary approaches and leadership," says Robin Marsh, co-director of the program with David Zilberman, UC Berkeley agricultural economist.

The heart of the program is a 3-week intensive summer certificate course in sustainable environmental management, which seeks to provide highlevel training for mid-career academics and environmental professionals from around the world; facilitate cross-learning among global peers; and offer opportunities for UC faculty to learn from the "onthe-ground" experiences of participants. About 75 people completed the course in 2001 and 2002.

The majority of course participants develop a "leadership change contract," which outlines how they will implement the new ideas they have acquired. Furthermore, a new small grants initiative, funded by the Goldman Fund and Packard Foundation, will provide $\$ 5,000$ to $\$ 10,000$ grants to assist participants with implementing their plans together with UC Berkeley collaborators.

For example, Yamoah and Oscar Arruda d'Alva, executive director of the Instituto Sertao in Brazil, began discussions this summer about joining forces to develop community-based programs for combating desertification. "The program has taken me out of my reality and enabled me to make contact with other people working on environmental issues," Arruda says. Likewise, participants from Kenya and Uganda teamed up with a fellow program alumnus from Finland to form a nonprofit

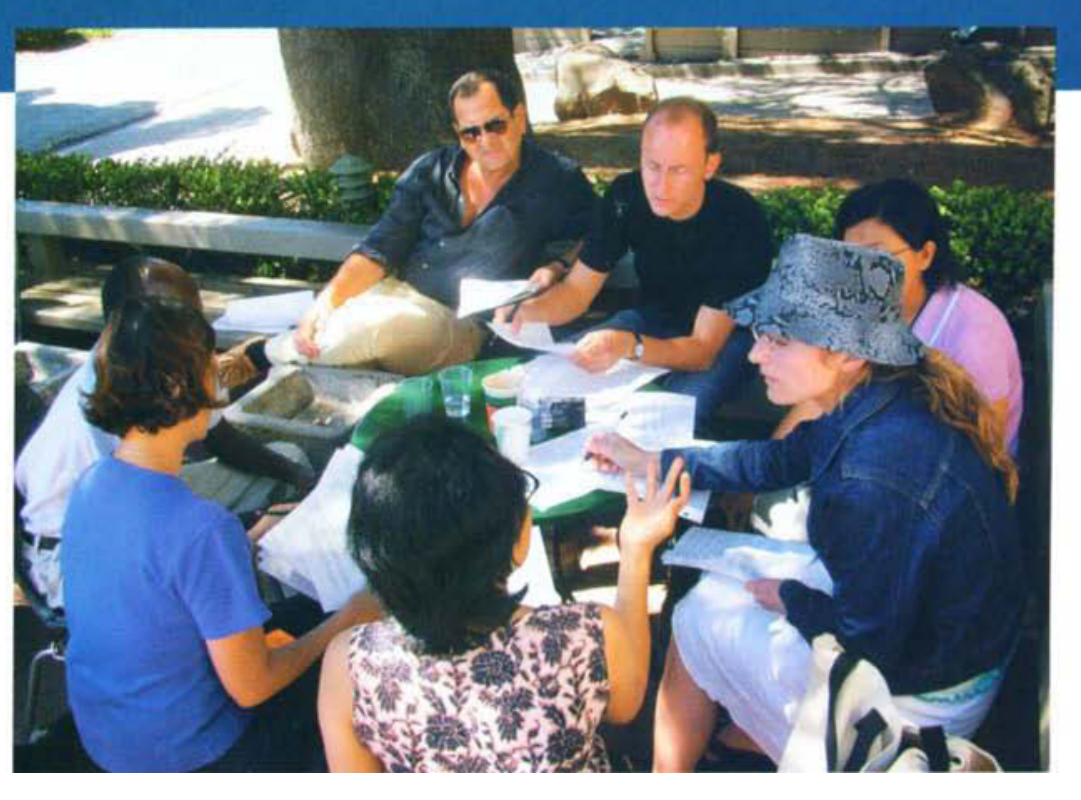

The Beahrs Environmental Leadership Program brings environmental professionals from around the world to UC Berkeley for a 3-week summer course. Participants are encouraged to form ongoing, collaborative working relationships with each other and UC faculty.

foundation that will fight poverty in East Africa.

In addition to workshops and panel discussions, the 2002 course included field tours of sustainable winegrowing techniques in Napa Valley and the Agroecology Center at UC Santa Cruz, as well as a 4-day case study of community forestry and participatory forest research in Trinity and Plumas counties. "The Beahrs program provides an international showcase for the Division's world-class research and extension programs," Zilberman says.

The program has developed several mechanisms to facilitate ongoing contacts among participants, including mentored fellowships with UC faculty, a Web-based alumni network, an information clearinghouse and alumni newsletters. A pilot Beahrs "satellite center" is under way in the Philippines in conjunction with the Southeast Asian Graduate Research Center in Agriculture (SEARCA), which will offer environmental management training workshops in Asia and encourage collaborative research with UC Berkeley faculty.

Over the next 3 to 5 years, Marsh says the

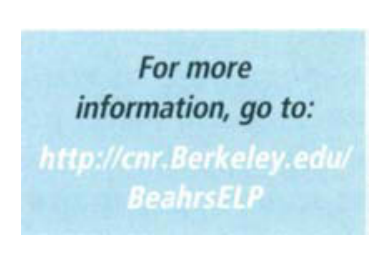

Beahrs program would like to raise an endowment, update and expand the course curriculum, strengthen its leadership component via partnership with the UC Berkeley Haas School of Business, and further develop the alumni network. Perhaps the most critical outcome will be the connections that participants make with each other and the joint projects that result.

"I will always cherish this network. I will stay in touch with them," says Beahrs program graduate J.K. Ladha of India, UC Davis adjunct professor and soil scientist with the International Rice Research Institute. "I have a strong feeling that they will become environmental leaders in their countries."

- Janet Byron 